\title{
Dimensionless Analysis on the Characteristics of Pneumatic Booster Valve with Energy Recovery
}

\author{
Fan Yang, ${ }^{1,2}$ Kotaro Tadano, ${ }^{2}$ Gangyan Li, ${ }^{1}$ and Toshiharu Kagawa ${ }^{2}$ \\ ${ }^{1}$ School of Mechanical and Electrical Engineering, Wuhan University of Technology, Wuhan 430070, China \\ ${ }^{2}$ Precision and Intelligence Laboratory, Tokyo Institute of Technology, Yokohama 226-0026, Japan \\ Correspondence should be addressed to Fan Yang; yang_fan@whut.edu.cn and Gangyan Li; gangyanli@whut.edu.cn
}

Received 1 May 2016; Accepted 4 August 2016

Academic Editor: Vittorio Zampoli

Copyright (c) 2016 Fan Yang et al. This is an open access article distributed under the Creative Commons Attribution License, which permits unrestricted use, distribution, and reproduction in any medium, provided the original work is properly cited.

\begin{abstract}
Factories are increasingly reducing their air supply pressures in order to save energy. Hence, there is a growing demand for pneumatic booster valves to overcome the local pressure deficits in modern pneumatic systems. To further improve energy efficiency, a new type of booster valve with energy recovery (BVER) is proposed. The BVER principle is presented in detail, and a dimensionless mathematical model is established based on flow rate, gas state, and energy conservation. The mathematics model was transformed into a dimensionless model by accurately selecting the reference values. Subsequently the dimensionless characteristics of BVER were found. BVER energy efficiency is calculated based on air power. The boost ratio is found to be mainly affected by the operational parameters. Among the structural ones, the recovery/boost chamber area ratio and the sonic conductance of the chambers are the most influential. The boost ratio improves by $15 \%-25 \%$ compared to that of a booster valve without an energy recovery chamber. The efficiency increases by $5 \%-10 \%$ depending on the supply pressure. A mathematical model is validated by experiment, and this research provides a reference for booster valve optimisation and energy saving.
\end{abstract}

\section{Introduction}

Pneumatic systems are widely used because of their low cost, high reliability, simplicity, and ease of maintenance. They typically account for $10 \%-20 \%$ of most national industrial electricity consumption [1]. Growing economic and environmental concerns indicate that pneumatic efficiency is the major constraint on system development, and improving them is now a major concern. Previous research has shown that decreasing the supply pressure by $0.1 \mathrm{MPa}$ leads to an $8 \%$ drop in energy consumption [2]. Many factories save energy in this way. Consequently, they have insufficient pneumatic pressure to drive heavy loads or operate highpressure equipment. Thus, more efficient pneumatic booster valves are being sought by industries to locally increase the pressures.

Compressed-air energy savings can be made by minimising leaks and pressure loss and by optimising the system [3]. In general, the basic way to enhance system efficiency is to decrease the energy input and increase the energy output. For the former, reducing the supply pressure has already been mentioned. High-pressure ratio in a booster valve indicates that the supply pressure can be lower for the same pressure output. An asymmetric booster valve has been proposed $[4,5]$ but its high boost ratio came at the expense of flow rate as well as too much pressurised exhaust air. The expansion energy-used (EEU) booster valve has been proposed for reducing air supply $[6,7]$. This involves the air being cut off before the piston reaches the end of its stroke and using the expansion energy of the air for the remainder. However, this energy becomes insufficient when the supply pressure is lowered. To increase the energy output, recovering energy and minimising friction are widely adopted in driving cylinders [8-10]. The energy is recovered and stored in a tank for secondary use [8]. The discharge chamber of the cylinder can be linked with the charge one by differential driven $[9,10]$. This helps to enhance the efficiency but at the expense of the steadiness of piston's motion. Given that the return stroke of the cylinder is useless, an extra two-way solenoid value can be used to cut off the air supply to save energy [11]. The problems of previous studies can be summarised as follows: It is a waste to have pressurised exhaust air. The pressure ratio is limited 


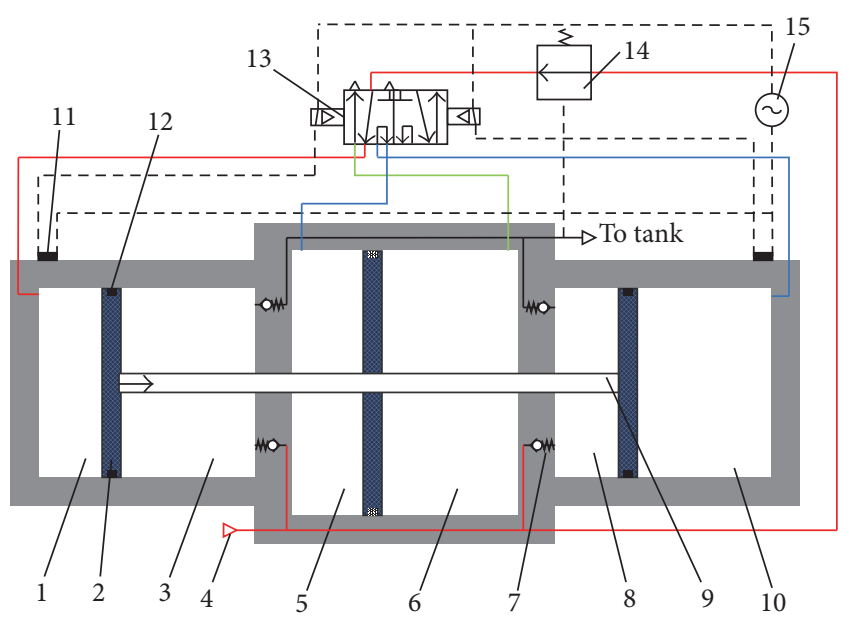

FIGURE 1: Booster valve with energy recovery (BVER) structure: (1) drive chamber A, (2) piston, (3) boost chamber A, (4) air source, (5) recovery chamber $A,(6)$ recovery chamber $B,(7)$ check valve, (8) boost chamber B, (9) piston rod, (10) drive chamber B, (11) magnetic switch, (12) magnetic ring, (13) two-position seven-port solenoid valve, (14) regulator, and (15) power source.

for a symmetric booster valve. Further, more energy used in the cylinder would be recovered if pressure fluctuations were reduced.

To solve these problems, a new type of booster valve with energy recovery (BVER; patent pending [12]) is proposed here. Its main performance characteristics are studied systematically using a dimensionless method [13-15] based on boost pressure ratio, flow rate, pressure fluctuation, and energy efficiency, the results from which provide the basis for booster-valve optimisation.

\section{BVER Principles}

In a traditional booster valve, compressed air in the drive chamber exhausts directly to the atmosphere, causing significant energy loss over time. In order to recover some of the lost energy, a BVER has two recovery chambers but the discharge chamber is not linked directly with the charge one. This helps to recover energy that flows into the recovery chamber instead of the driver one to avoid large pressure fluctuations. A schematic diagram of a BVER is shown in Figure 1. It comprises two boost chambers, two recovery chambers, four check valves, a regulator, a magnetic switch, and a two-position seven-port solenoid valve. The structure of the solenoid valve is shown in Figure 2, which helps to improve the integrated level of the BVER.

The piston is located initially at the left and moves to the right as shown in Figure 1. The solenoid valve is in the state shown in Figure 2, in which one branch of the air source connects with booster chamber B while the other connects with driver chamber A through the regulator and the solenoid valve. As air flows into these two chambers, its pressure rises and generates thrust to drive the piston to the right, thus reducing the volume of boost chamber A. As a result, the pressure in that chamber increases until

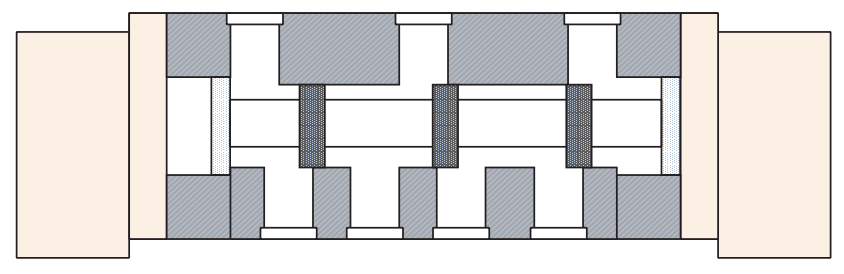

Figure 2: Two-position seven-port solenoid valve.

it is higher than that in the tank. The check valve then opens and the boost chamber air begins to exhaust to the tank. Meanwhile, as the piston moves to the right, the air in drive chamber B is recycled by recovery chamber A and is reused by pushing the piston, while the low-pressure air in recovery chamber $\mathrm{B}$ discharges to the atmosphere. When the piston reaches the right end, a magnetic signal is generated to change the solenoid-valve state. The discharge and charge chambers exchange roles so the piston can move in reverse and discharge high-pressure air twice each cycle. Setting the regulator (14 in Figure 2) to a different opening changes the boost ratio. When the output pressure is sufficiently high, it drives the regulator to decrease the opening; overpressure protection limits the out pressure to protect the system.

The air in the drive chamber flows into the recovery one through the solenoid valve rather than exhausting to the atmosphere. Its energy is reused in pushing the piston, which helps to increase the boost ratio and energy efficiency by recovering the high-pressure gas.

\section{Mathematical Model and Nondimensionalization}

In order to analyse the BVER, the following assumptions were made:

(i) The air in the system is an ideal gas that is governed by the ideal gas law.

(ii) The system is leak-free, for example, piston and fittings.

(iii) The valve chambers are initially at atmospheric temperature, and the air source is equal to atmosphere pressure.

(iv) The dead volume of each chamber end can be neglected, and the volumes of the in-port are the same.

3.1. Mathematical Model of BVER. The BVER comprises six chambers in which the pressure, temperature, and volume vary with piston motion. Hence, its characteristics are described in principle by $>20$ equations. However, three chambers are discharging while the rest are charging during each stroke. The charge/discharge chambers have the same control equations but the structural parameters are different. Thus, the BVER is modelled mathematically in relation to its charge/discharge chambers. These models are then transferred to stand Simulink subsystems whose parameters 
can be redefined in simulation. This is an effective way of enhancing the modelling efficiency.

3.1.1. Gas State Equation. The chamber pressure, temperature, and volume satisfy the ideal gas law:

$$
p V=m R \theta
$$

The mass flux in the chambers is equal to that into or out of each chamber, so

$$
\pm G=\frac{d m}{d t}
$$

Differentiating (1) with respect to time, we have $p d V / d t=$ $p S u$ since the variable chamber volume is equal to $S x$. Hence, the pressures in the discharge and charge chambers are governed, respectively, by

$$
\begin{aligned}
V_{\mathrm{d}} \frac{d p_{\mathrm{d}}}{d t} & =-G_{\mathrm{d}} R \theta_{\mathrm{d}}+p_{\mathrm{d}} S_{\mathrm{d}} u+\frac{p_{\mathrm{d}} V_{\mathrm{d}}}{\theta_{\mathrm{d}}} \frac{d \theta_{\mathrm{d}}}{d t}, \\
V_{\mathrm{c}} \frac{d p_{\mathrm{c}}}{d t} & =G_{\mathrm{c}} R \theta_{\mathrm{c}}-p_{\mathrm{c}} S_{\mathrm{c}} u+\frac{p_{\mathrm{c}} V_{\mathrm{c}}}{\theta_{\mathrm{c}}} \frac{d \theta_{\mathrm{c}}}{d t} .
\end{aligned}
$$

3.1.2. Energy Conservation Equation. Given that each BVER chamber is a variable system and the system as a whole satisfies energy conservation (i.e., it is leak-free), the energy changes in the system can be expressed as

$$
d U=h d m+d W+d Q
$$

where $d U$ is the internal energy change, $h d m$ is the enthalpy in or out of the system, $d W$ is the work done on the system, and $d Q$ is the heat transfer from the cylinder wall.
A similar approach is applied to the gas state equation, leading to the temperature in each chamber being governed by

$$
\begin{aligned}
m_{\mathrm{d}} c_{v} \frac{d \theta_{\mathrm{d}}}{d t}= & -R \theta_{\mathrm{d}} G_{\mathrm{d}}+p_{\mathrm{d}} S_{\mathrm{d}} u+h S_{\mathrm{hd}}\left(\theta_{\mathrm{a}}-\theta_{\mathrm{d}}\right), \\
m_{\mathrm{c}} c_{v} \frac{d \theta_{\mathrm{c}}}{d t}= & c_{v} G_{\mathrm{c}}\left(\theta_{\mathrm{a}}-\theta_{\mathrm{c}}\right)+R \theta_{\mathrm{a}} G_{\mathrm{c}}-p_{\mathrm{c}} S_{\mathrm{c}} u \\
& +h S_{\mathrm{hc}}\left(\theta_{\mathrm{a}}-\theta_{\mathrm{c}}\right),
\end{aligned}
$$

where $S_{\mathrm{hd}}$ and $S_{\mathrm{hc}}$ are the heat exchange areas. These are always changing as the piston moves so they are taken to be half the inner cylinder area to facilitate modelling.

3.1.3. Flow-Rate Equation. The main pneumatic flow-rate parameters are the sonic conductance and critical pressure ratio defined by ISO6358. The flow rate depends on the upstream pressure, temperature, and pressure ratio, while the mass flux in or out of each chamber can be expressed as

$$
G=C p_{1} \rho_{0} \sqrt{\frac{\theta_{0}}{\theta_{1}}} \varphi(p),
$$

where $\varphi(p)$ is a function of the pressure ratio and determines whether the flow is a chock or subsonic one:

$$
\varphi(p)= \begin{cases}1 & \frac{p_{2}}{p_{1}} \leq b \\ \left(1-\left(\frac{p_{2} / p_{1}-b}{1-b}\right)^{2}\right)^{0.5} & b<\frac{p_{2}}{p_{1}} \leq 1 .\end{cases}
$$

3.1.4. Piston Motion Equation. The pressure and force distributions on the piston are illustrated in Figure 3 for the piston moving from left to right.

The piston equation of motion can be determined by Newton's second law:

$$
M \frac{d u}{d t}= \begin{cases}\left(p_{\mathrm{da}}-p_{\mathrm{db}}\right) S_{\mathrm{da}}-\left(p_{\mathrm{ba}}-p_{\mathrm{bb}}\right) S_{\mathrm{ba}}+\left(p_{\mathrm{ra}}-p_{\mathrm{rb}}\right) S_{\mathrm{ra}}-F_{\mathrm{f}}, & x \neq 0, L \\ 0, & x=0, L .\end{cases}
$$

The friction force $F_{\mathrm{f}}$ on the piston can be represented by a mixed friction model comprising Coulomb and viscous frictions [16]:

$$
F_{\mathrm{f}}=c u+ \begin{cases}F_{\mathrm{sf}} & u=0 \\ F_{\mathrm{df}} \operatorname{sign}(u) & u \neq 0\end{cases}
$$

where $F_{\mathrm{sf}}$ is the maximum static friction and $F_{\mathrm{df}}$ is the dynamic friction whose direction depends on the piston velocity.

3.1.5. Pressure in the Tank. Booster valves are always used with tank to decrease pressure fluctuations; the opening of the BVER check valve depends on the tank pressure. Pressure feedback exists between the BVER and the tank, so an associated BVER/tank model helps improve the accuracy and reflect the real system output. The tank heat exchange area is sufficiently large for adequate heat exchange with the surroundings. It can be treated as an isothermal chamber with constant temperature, giving the tank pressure response as

$$
\frac{d p_{\mathrm{t}}}{d t}=\frac{R \theta_{\mathrm{a}}}{V_{\mathrm{t}}}\left(G_{\text {in }}-G_{\text {out }}\right)
$$

where $G_{\text {in }}$ is the air flow into the tank dependent on the BVER/tank pressure differential. The flow rate $G_{\text {out }}$ through 


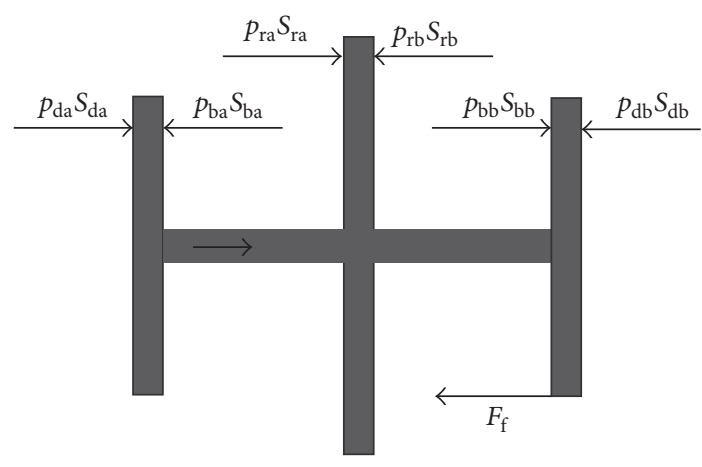

FIGURE 3: Piston force diagram.

the restriction is considered to be the real output of the booster system that is supplied directly to downstream devices.

3.2. Dimensionless Model of BVER. Dimensionless analysis can simplify problems in which we want to know the influence of each parameter. Each parameter in the model becomes dimensionless, indicating that dimensions have no effect on the results, which in turn become simpler. In other words, if we know the value of a parameter relative to its reference value, we can understand its performance irrespective of the type of BVER.

3.2.1. Dimensionless Parameters. To nondimensionalise the equations derived in Section 2, 11 reference values were determined as shown in Table 1. These were chosen as follows:

(i) The parameter value is a known quantity, for example, $p_{\mathrm{s}}, \theta_{\mathrm{a}}$.

(ii) The parameter value is relatively large or can be easily decreased, for example, $L, C_{\mathrm{da}}$.

(iii) The parameter can be derived directly from other reference values, for example, $V_{\mathrm{da}}, G_{0}$, and $u_{0}$.

3.2.2. Dimensionless Gas State Equations. Substituting the reference values into (3) and (4), the dimensionless gas state equations are given by

$$
\begin{aligned}
& V_{\mathrm{d}}^{*} \frac{d p_{\mathrm{d}}^{*}}{d t^{*}}=-G_{\mathrm{d}}^{*} \theta_{\mathrm{d}}^{*}+p_{\mathrm{d}}^{*} S_{\mathrm{d}}^{*} u^{*}+\frac{p_{\mathrm{d}}^{*} V_{\mathrm{d}}^{*}}{\theta_{\mathrm{d}}^{*}} \frac{d \theta_{\mathrm{d}}^{*}}{d t^{*}}, \\
& V_{\mathrm{c}}^{*} \frac{d p_{\mathrm{c}}^{*}}{d t^{*}}=G_{\mathrm{c}}^{*} \theta_{\mathrm{c}}^{*}-p_{\mathrm{c}}^{*} S_{\mathrm{c}}^{*} u^{*}+\frac{p_{\mathrm{c}}^{*} V_{\mathrm{c}}^{*}}{\theta_{\mathrm{c}}^{*}} \frac{d \theta_{\mathrm{c}}^{*}}{d t^{*}} .
\end{aligned}
$$

3.2.3. Dimensionless Energy Conservation Equations. Similarly, converting the energy conservation equations to dimensionless quantities gives

$$
\begin{aligned}
\frac{d \theta_{\mathrm{d}}^{*}}{d t^{*}}= & \frac{G_{\mathrm{d}}^{*} \theta_{\mathrm{d}}^{* 2}}{p_{\mathrm{d}}^{*} V_{\mathrm{d}}^{*}}(1-\kappa)+\frac{\theta_{\mathrm{d}}^{*} S_{\mathrm{d}}^{*} u^{*}}{V_{\mathrm{d}}^{*}}(\kappa-1) \\
& +K_{\mathrm{a}}\left(1-\theta_{\mathrm{d}}^{*}\right), \\
\frac{d \theta_{\mathrm{c}}^{*}}{d t^{*}}= & \frac{G_{\mathrm{c}}^{*} \theta_{\mathrm{c}}^{*}}{p_{\mathrm{c}}^{*} V_{\mathrm{c}}^{*}}\left(\kappa-\theta_{\mathrm{c}}^{*}\right)-\frac{\theta_{\mathrm{c}}^{*} S_{\mathrm{c}}^{*} u^{*}}{V_{\mathrm{c}}^{*}}(\kappa-1) \\
& +K_{\mathrm{a}}\left(1-\theta_{\mathrm{c}}^{*}\right),
\end{aligned}
$$

where $K_{\mathrm{a}}$ is the Kagawa coefficient [17] reflecting the rapidity of heat exchange between the inner cylinder and its surroundings. This can be defined as

$$
K_{\mathrm{a}}=\frac{T_{\mathrm{p}}}{T_{\mathrm{h}}}=\frac{S_{\mathrm{h}} h \theta^{*}}{c_{v} G_{0} p^{*}} .
$$

3.2.4. Dimensionless Flow-Rate Equation. When the dimensionless pressure ratio of the restriction is less than the critical pressure $b$ (i.e., $p_{2}^{*} / p_{1}^{*} \leq b$ ), the dimensionless flow rate is

$$
G^{*}=C_{i}^{*} p_{1}^{*} \sqrt{\frac{1}{\theta_{1}^{*}}}
$$

When $b<p_{2}^{*} / p_{1}^{*} \leq 1$, the dimensionless flow rate is

$$
G^{*}=C_{i}^{*} p_{1}^{*} \sqrt{\frac{1}{\theta_{1}^{*}}}\left(1-\left(\frac{p_{2}^{*} / p_{1}^{*}-b}{1-b}\right)^{2}\right)^{0.5} .
$$

3.2.5. Dimensionless Equation of Motion. The natural period $T_{\mathrm{f}}$ and the inertia $J$ were introduced to simply (9) [18]. The dimensionless equation of motion can then be obtained by dividing (9) by $M u_{0} / T_{\mathrm{p}}$. The natural period of the BVER is

$$
T_{\mathrm{f}}=2 \pi \sqrt{\frac{M L}{p_{\mathrm{s}} S_{\mathrm{da}}}}
$$

and the inertia coefficient is

$$
J=\frac{S_{\mathrm{da}} p_{\mathrm{s}} L}{M u_{0}^{2}}
$$

Substituting (17) and (18) into (9), the dimensionless equation of motion becomes

$$
\frac{d u^{*}}{d t^{*}}= \begin{cases}\left(\frac{2 \pi}{T_{\mathrm{f}}^{*}}\right)^{2}\left(\left(p_{\mathrm{da}}^{*}-p_{\mathrm{db}}^{*}\right)-\left(p_{\mathrm{ba}}^{*}-p_{\mathrm{bb}}^{*}\right) S_{\mathrm{ba}}^{*}+\left(p_{\mathrm{ra}}^{*}-p_{\mathrm{rb}}^{*}\right) S_{\mathrm{ra}}^{*}-F_{\mathrm{f}}^{*}\right), & x^{*} \neq 0,1 \\ 0, & x^{*}=0,1\end{cases}
$$


TABLE 1: Dimensionless parameters.

\begin{tabular}{|c|c|c|c|}
\hline Parameters & & Reference & Dimensionless \\
\hline Pressure & $p_{\mathrm{s}}$ & Supply pressure & $p^{*}=\frac{p}{p_{s}}$ \\
\hline Temperature & $\theta_{\mathrm{a}}$ & Atmospheric temperature & $\theta^{*}=\frac{\theta}{\theta_{\mathrm{a}}}$ \\
\hline Volume & $V_{\mathrm{da}}=S_{\mathrm{da}} L$ & Volume of drive chamber A & $V^{*}=\frac{V}{V_{\mathrm{da}}}$ \\
\hline Sonic conductance & $C_{\mathrm{da}}$ & Sonic conductance of drive chamber A & $C^{*}=\frac{C}{C_{\mathrm{da}}}$ \\
\hline Piston area & $S_{\mathrm{da}}$ & Piston area of drive chamber $\mathrm{A}$ & $S^{*}=\frac{S}{S_{\mathrm{da}}}$ \\
\hline Mass flow rate & $G_{0}=C_{\mathrm{da}} p_{\mathrm{s}} \rho_{0} \sqrt{\frac{\theta_{0}}{\theta_{\mathrm{a}}}}$ & Flow rate under reference pressure, temperature, and sonic conductance & $G^{*}=\frac{G}{G_{0}}$ \\
\hline Velocity & $u_{0}=\frac{R C_{\mathrm{da}} \rho_{0}}{S_{\mathrm{da}}} \sqrt{\theta_{\mathrm{a}} \theta_{0}}$ & Piston velocity under reference flow rate & $u^{*}=\frac{u}{u_{0}}$ \\
\hline Stroke & $L$ & Piston stroke & $x^{*}=\frac{x}{L}$ \\
\hline Time & $T_{\mathrm{p}}=\frac{L}{u_{0}}$ & Motion time of piston under $u_{0}$ & $t^{*}=\frac{t}{T_{\mathrm{P}}}$ \\
\hline Energy & $E_{0}=p_{\mathrm{s}} V_{\mathrm{da}}$ & Energy under reference pressure and volume & $E^{*}=\frac{E}{E_{0}}$ \\
\hline Air power & $P_{0}=\frac{E_{0}}{T_{\mathrm{p}}}$ & Air power with reference energy and time & $P^{*}=\frac{P}{P_{0}}$ \\
\hline
\end{tabular}

The dimensionless friction force and other parameters are given as follows:

$$
\begin{aligned}
& F_{\mathrm{f}}^{*}=c^{*} u^{*}+ \begin{cases}F_{\mathrm{sf}}^{*} & u^{*}=0 \\
F_{\mathrm{df}}^{*} \operatorname{sign}(u) & u^{*} \neq 0,\end{cases} \\
& c^{*}=\frac{c u_{0}}{p_{\mathrm{s}} S_{\mathrm{da}}}, \\
& F_{\mathrm{sf}}^{*}=\frac{F_{\mathrm{sf}}}{p_{\mathrm{s}} S_{\mathrm{da}}}, \\
& F_{\mathrm{df}}^{*}=\frac{F_{\mathrm{df}}}{p_{\mathrm{s}} S_{\mathrm{da}}} .
\end{aligned}
$$

3.2.6. Dimensionless Pressure Response in Tank. With the reference values in Table 1, (11) can be made dimensionless as

$$
\frac{d p_{\mathrm{t}}^{*}}{d t^{*}}=\frac{G_{\mathrm{in}}^{*}-G_{\mathrm{out}}^{*}}{V_{\mathrm{t}}^{*}}
$$

\section{Simulation Model and Analysis}

4.1. Simulation Model and Parameter Determination. The gas state and energy conservation equations are different for the charge and discharge chambers, but the flow-rate one is the same. Five standard subsystems were modelled
TABLE 2: Initial simulation values.

\begin{tabular}{cccccccccccc}
\hline$C_{\mathrm{b}}^{*}$ & $C_{\mathrm{r}}^{*}$ & $S_{\mathrm{ra}}^{*}$ & $K_{\mathrm{a}}$ & $T_{\mathrm{f}}^{*}$ & $F_{\mathrm{sf}}^{*}$ & $F_{\mathrm{df}}^{*}$ & $c^{*}$ & $C_{\mathrm{th}}^{*}$ & $V_{\mathrm{t}}^{*}$ & $p_{\mathrm{r}}^{*}$ & $p_{\mathrm{a}}^{*}$ \\
\hline 0.8 & 3.0 & 1.5 & 1.0 & 0.2 & 0.016 & 0.01 & 0.012 & 0.3 & 10 & 1.0 & 0.2 \\
\hline
\end{tabular}

in MATLAB/Simulink based on the control equations in Section 3. Combining these and the tank model, a BVER simulation model was established according to the work flow shown in Figure 4. The control equations were solved using the ODE45 solver with a variable step size, in order to judge the stroke end automatically.

The reference parameters in Table 1 were set to unity in the simulation program. The initial values of the other parameters are shown in Table 2; these can be divided into two categories: structural or operational. Structural parameters are the original design ones that cannot be changed and so should be configured properly when designed. Operational parameters are those that can be adjusted by the user. Details of these dimensionless parameters are shown in Main BVER Parameters in Nomenclature.

With these parameter settings, the BVER system characteristics can be solved as shown in Figures 5 and 6, where the ordinates are dimensionless values.

Figure 5 shows the pressure and flow-rate responses in the BVER and the tank. Initially, the former cannot reach the required boost ratio for the low restriction in the latter. The BVER works at high frequency and has large exhaustpressure fluctuations. As the tank pressure increases, the 


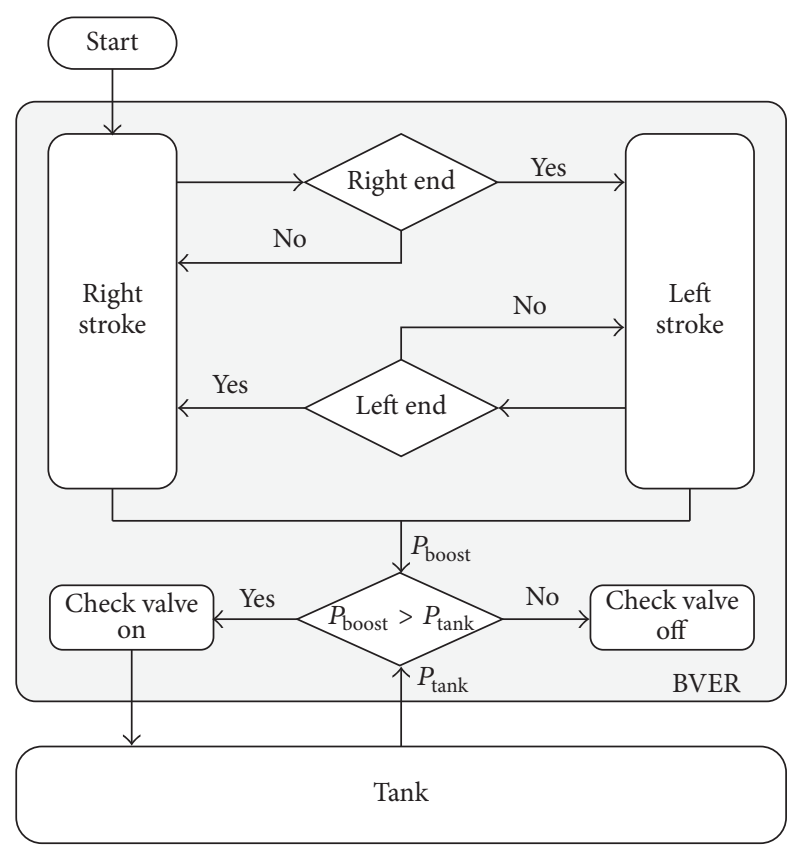

FIGURE 4: Work flow of BVER.
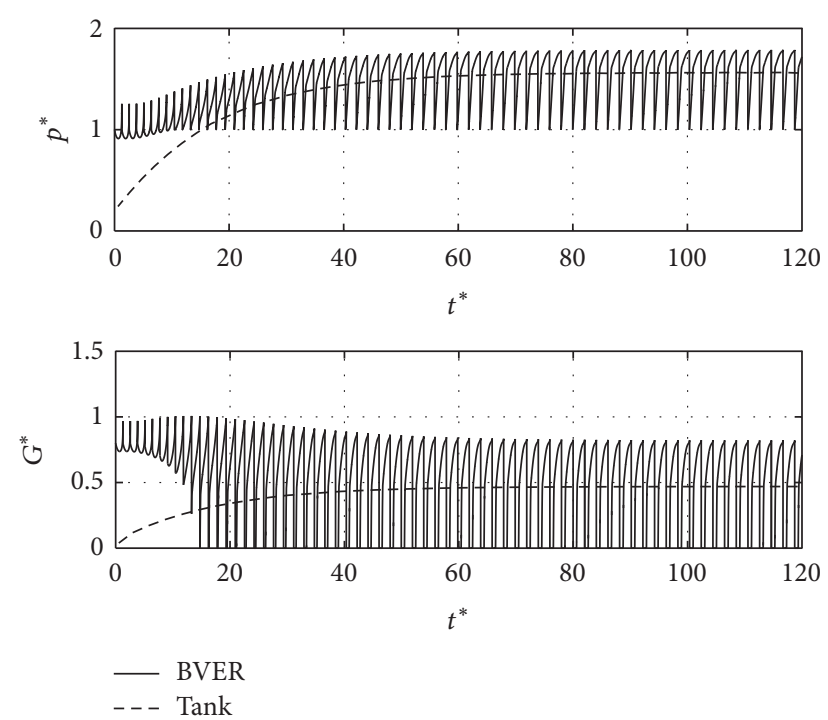

FIgURE 5: Pressure and flow rate of BVER and tank.

operational cycle, boost ratio, and flow rate stabilise gradually. The tank pressure and flow rate are clearly smaller than those of the BVER and are discontinuous when the piston changes direction, so they reflect the real output of the BVER.

The piston motion is shown in Figure 6 when the BVER works in its steady state. The velocity fluctuates when the piston changes direction, but otherwise it is steady.

4.2. Influence of Structural Parameters. The structural parameters in Nomenclature are changed first for comparison. Because the tank pressure represents the real BVER output, we focused on the pressure response variation in the tank.
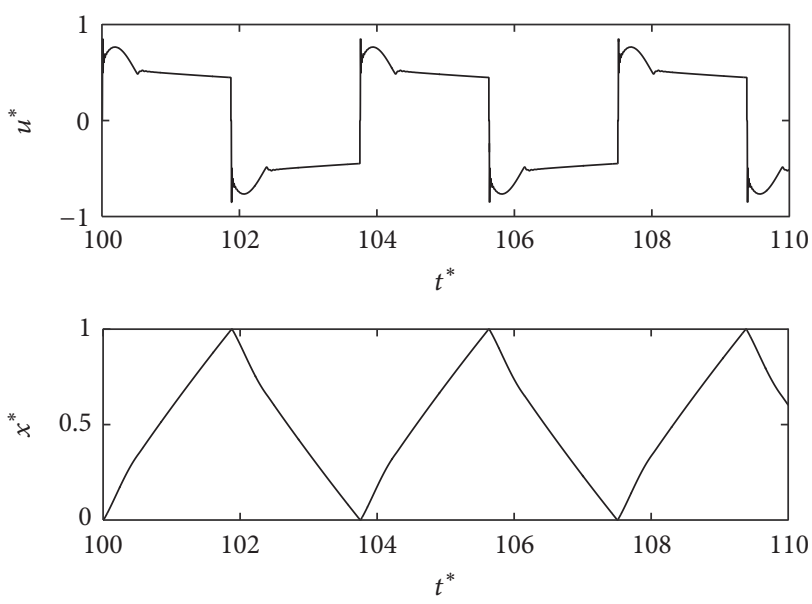

FIgURE 6: Velocity and displacement of piston.

Figure 7 shows the tank pressure response according to different structural parameters.

Figures 7(a) and 7(b) show that the sonic conductance of the boost chambers has an obvious effect on the BVER pressure response. This is because the flow rate is determined by the sonic conductance. With increasing sonic conductance $C_{\mathrm{b}}^{*}$, the pressurised gas can be exhausted to the tank immediately. However, it reaches its maximum when $C_{\mathrm{b}}^{*}=2.0$ because the flow rate is finite. Similarly, by increasing the sonic conductance $C_{r}^{*}$, the pressurised gas can be exhausted to the atmosphere immediately to avoid negative work. As it increases, so does the boost ratio.

Figure 7(c) shows that the boost ratio increases with increasing area ratio. The recovered gas can output more energy to drive the piston as the area of the recovery chamber increases, thus increasing the boost ratio as the area ratio increases. However, a finite amount of air is recovered because the drive chamber volume is constant; hence, it does not increase for $S_{\mathrm{r}}^{*} \leq 2.0$.

Figures $7(\mathrm{~d})$ to $7(\mathrm{~h})$ show that the influences of these five parameters are relatively small. This is because the heat energy and friction force are smaller than the pressure energy and pressure-driven force, respectively.

4.3. Influence of Operational Parameters. The BVER performance is different depending on its running conditions, so the operational parameters were changed to determine the BVER characteristics for different operational conditions.

4.3.1. Influence of Load Characteristic. The load characteristic is the compressed-air consumption of the downstream devices. We used different throttle-valve openings to simulate the diversity of devices. This means the sonic conductance of the throttle valve is changed through the simulation. Figure 8 shows the pressure response in the BVER and tank. It is clear that the BVER boost ratio decreases as the load increases and that the pressure output of the booster valve system is much lower than that of the BVER. For example, when $C_{\mathrm{th}}^{*}=$ 0.7 , the BVER boost ratio is 1.4 but the tank output pressure 

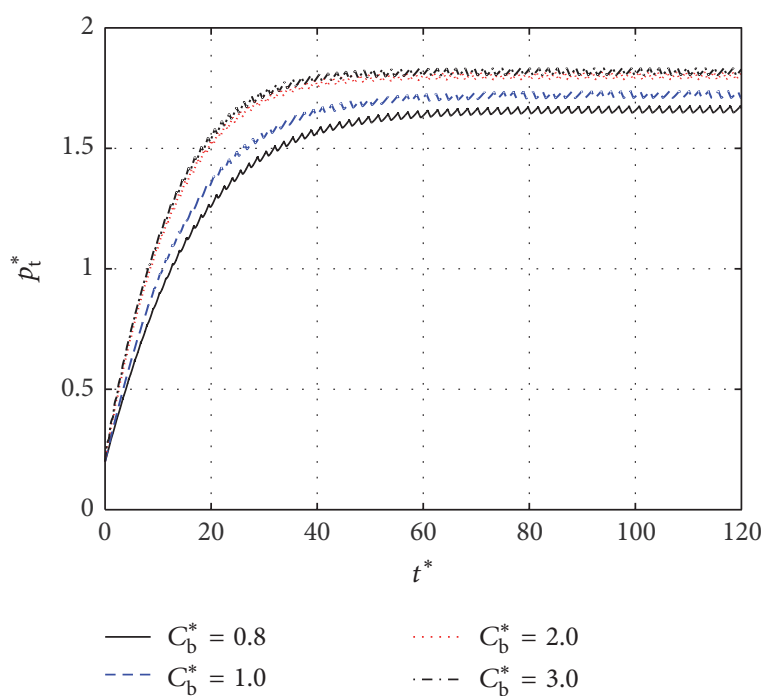

(a) Pressure response with $C_{\mathrm{b}}^{*}$

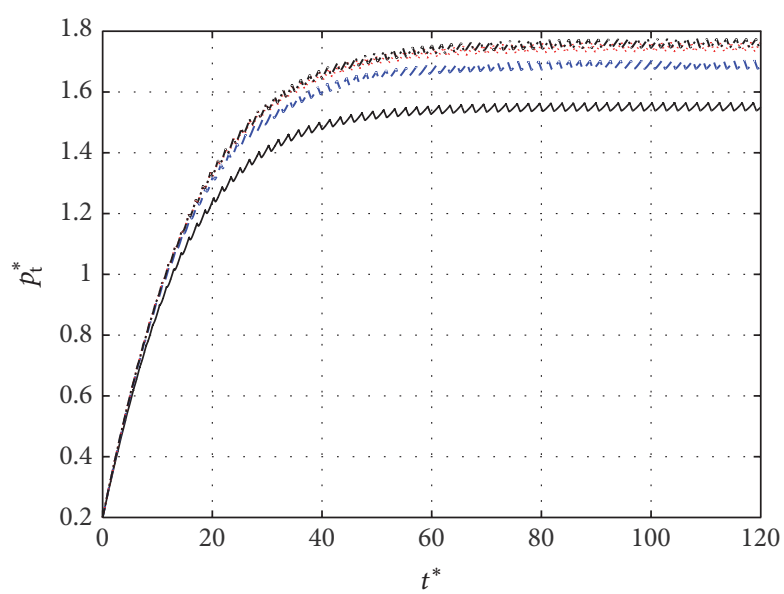

$$
\begin{aligned}
& -S_{\mathrm{r}}^{*}=1.1 \\
& --S_{\mathrm{r}}^{*}=1.5
\end{aligned}
$$

(c) Pressure response with $S_{\mathrm{r}}^{*}$

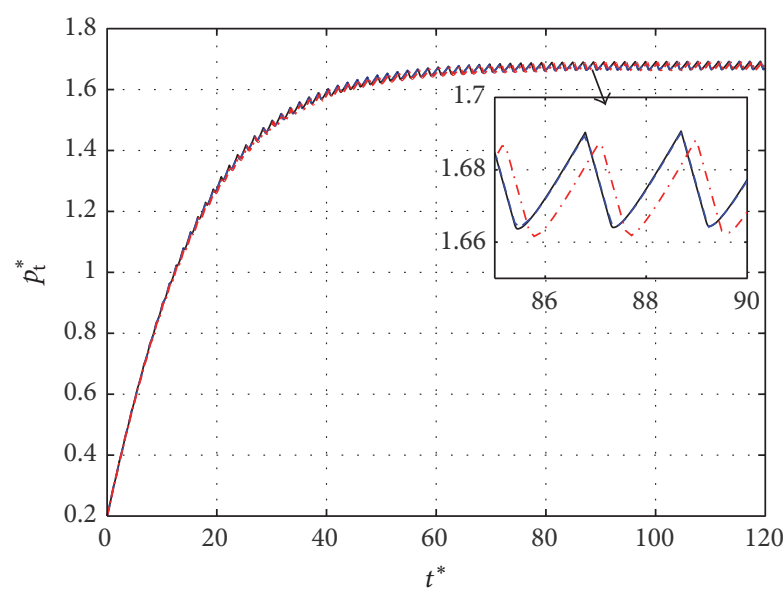

$$
\begin{aligned}
& -T_{\mathrm{f}}^{*}=0.1 \\
& ---T_{\mathrm{f}}^{*}=0.2
\end{aligned}
$$

(e) Pressure response with $T_{\mathrm{f}}^{*}$

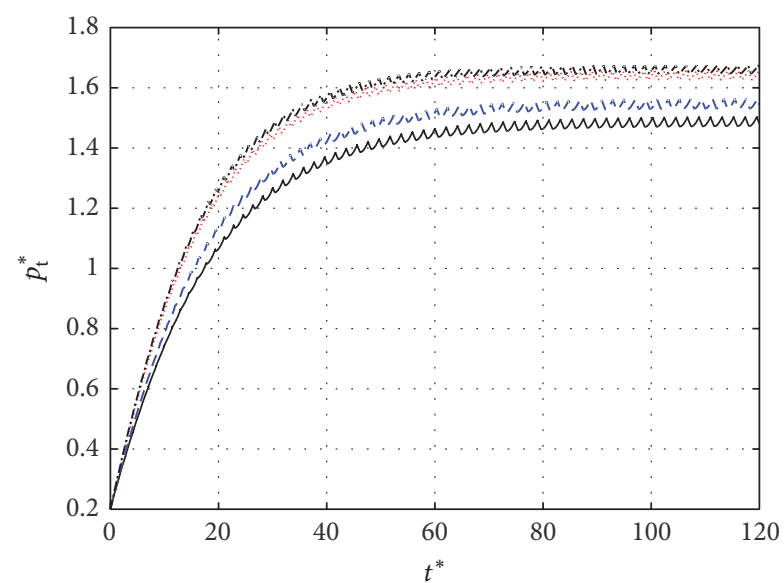

$$
\begin{aligned}
-C_{\mathrm{r}}^{*}=0.8 & \cdots \cdots C_{\mathrm{r}}^{*}=2.0 \\
--C_{\mathrm{r}}^{*}=1.0 & \cdots-C_{\mathrm{r}}^{*}=3.0
\end{aligned}
$$

(b) Pressure response with $C_{\mathrm{r}}^{*}$

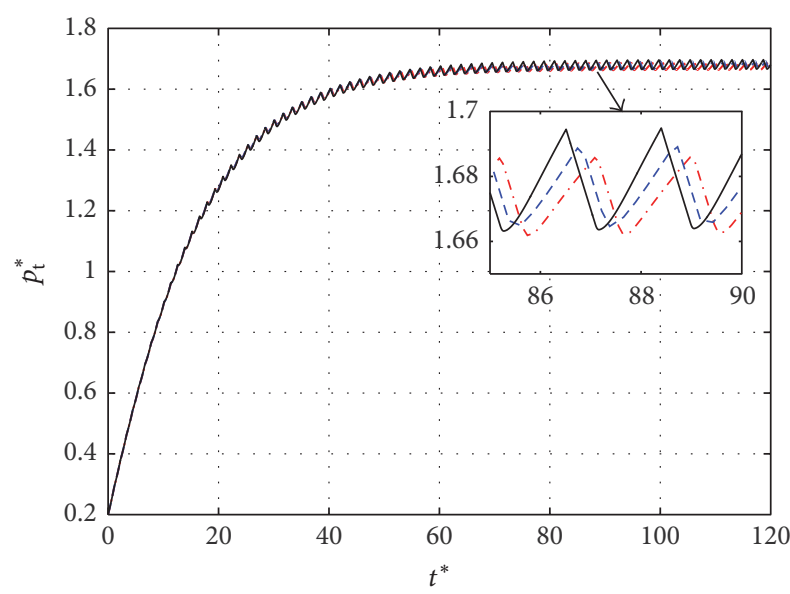

$$
\begin{array}{ll}
--K_{\mathrm{a}} & =0 \\
--K_{\mathrm{a}} & =1
\end{array} \quad-K_{\mathrm{a}}=10
$$

(d) Pressure response with $K_{\mathrm{a}}$

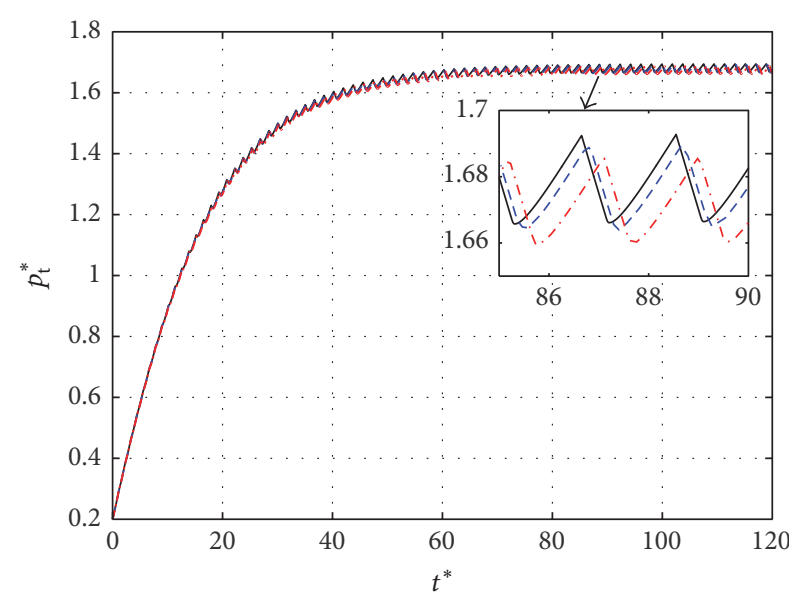

$$
\begin{aligned}
c^{*} & =0.006 \\
---c^{*}=0.012 & -.-c^{*}=0.024
\end{aligned}
$$

(f) Pressure response with $c^{*}$

Figure 7: Continued. 


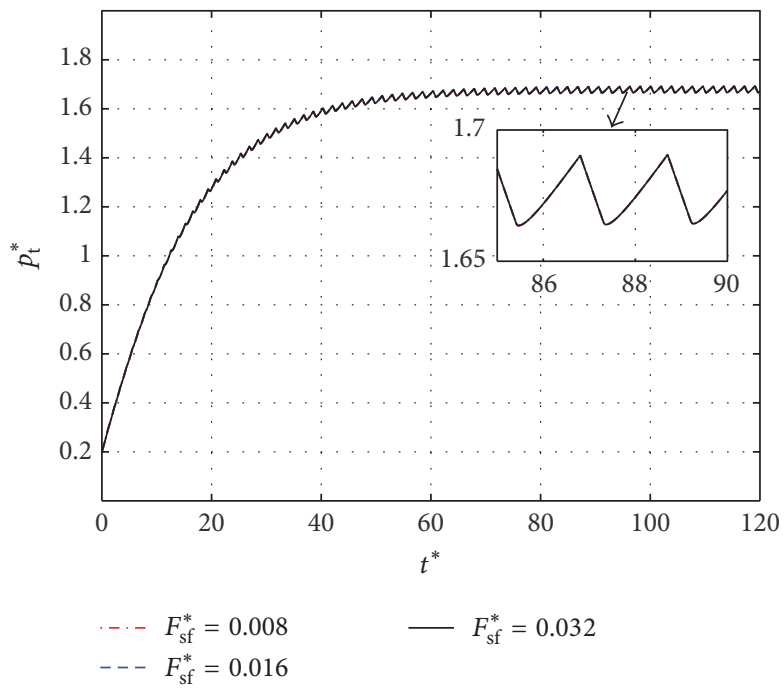

(g) Pressure response with $F_{\text {sf }}^{*}$

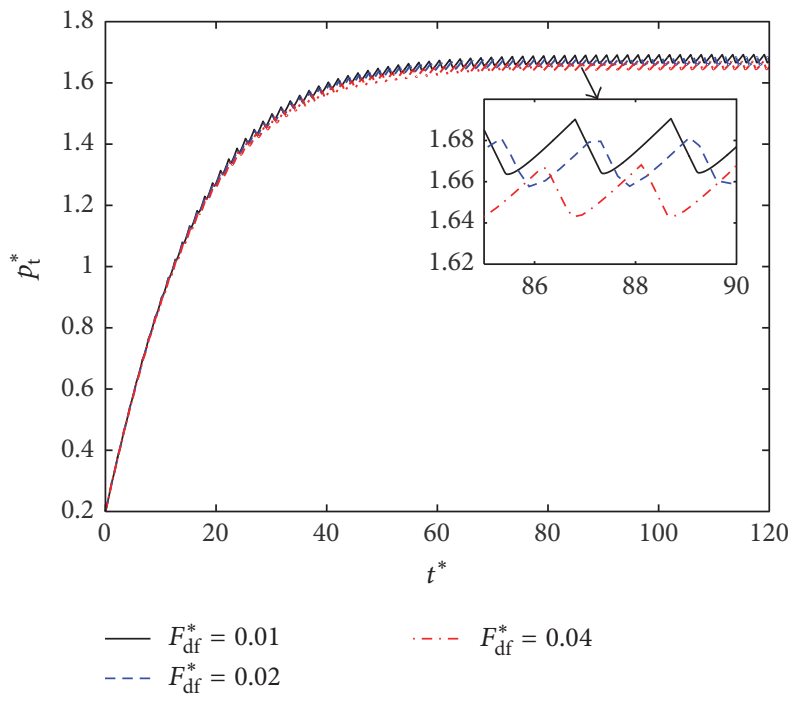

(h) Pressure response with $F_{\mathrm{df}}^{*}$

FIgURE 7: Influence of structural parameters.
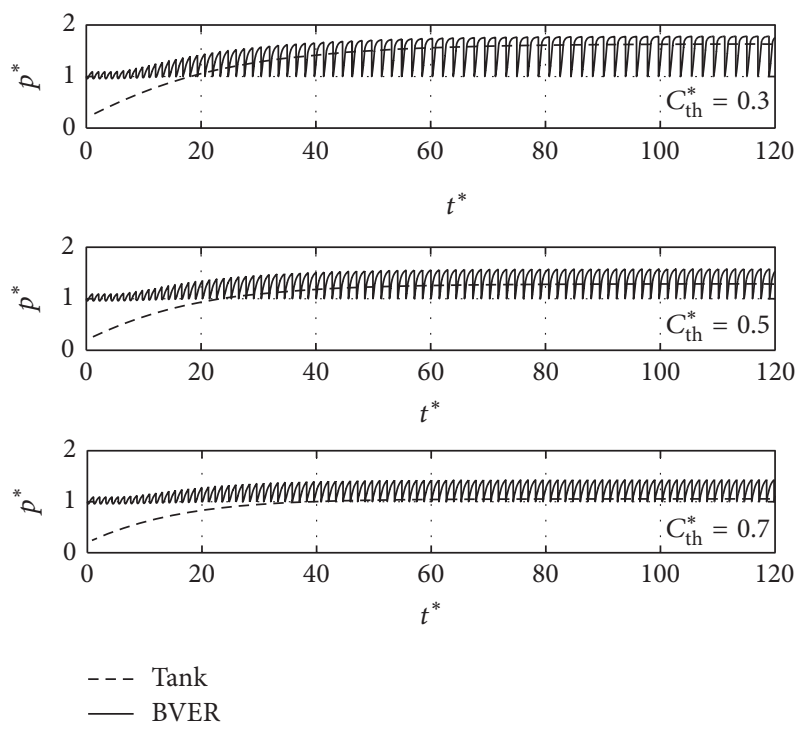

Figure 8: Pressure responses of BVER and tank.

is approximately equal to the supply one, meaning that the BVER does not boost the pressure.

4.3.2. Influence of Tank Volume. Pressure fluctuations can be minimised by using a tank of the correct volume. Figure 9 illustrates the pressure responses in tanks of different volumes, and it also shows that tank volume has no effect on pressure magnitude. However, with increasing tank volume, a relatively steady pressure is achieved at the expense of the charging time.

The pressure fluctuations are shown in the maganified figure of Figure 9. When the (dimensionless) tank volume is 30 , the fluctuation amplitude is $<1 \%$. This helps to select a tank of the correct volume.

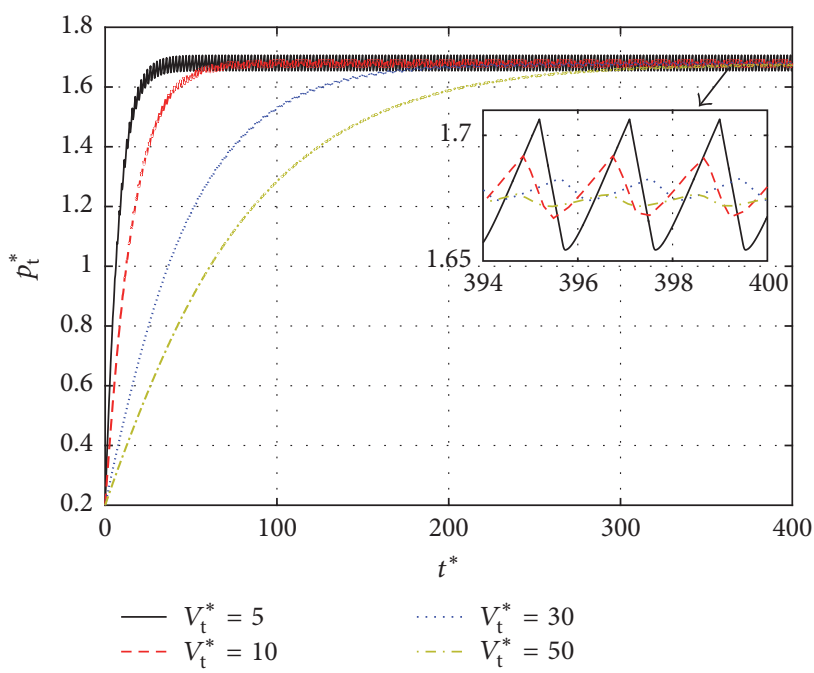

Figure 9: Pressure response with $V_{\mathrm{t}}^{*}$.

4.3.3. Influence of Regulator Coefficient. The regulator coefficient is the opening of the regulator (14 in Figure 1). When $P_{\mathrm{r}}=1.0$, the flow pressure in the drive chamber equals the supply pressure; as $P_{\mathrm{r}}$ decreases, so does the flow pressure. The pressure response is plotted in Figure 10.

Figure 10 shows that the boost ratio increases with the regulator coefficient. This is because the pressure in the drive chamber is controlled directly by the regulator coefficient; when the latter increases, the former increases simultaneously. This increases both the drive force and the boost ratio.

4.3.4. Influence of Supply Pressure. When the reference pressure is the supply one, the larger the value of $p_{a}^{*}$ the smaller the supply pressure. Figure 11 shows the relationship between 


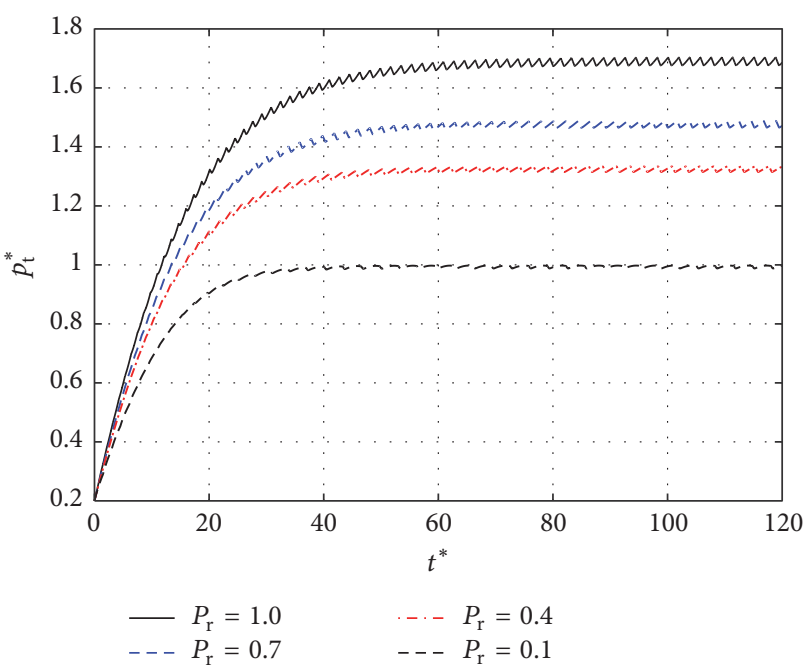

FIgURE 10: Pressure response with $P_{\mathrm{r}}$.

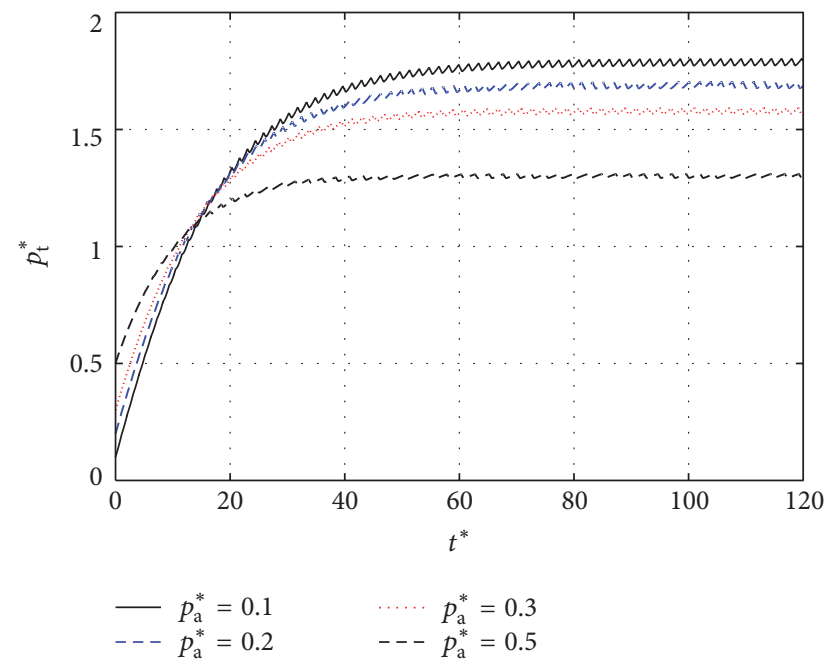

FIgURE 11: Pressure response with $p_{\mathrm{a}}^{*}$.

boost ratio and supply pressure. When the supply pressure increases, the boost ratio increases as more energy is supplied to the system to drive the piston. Consequently, the efficiency decreases as more energy exhausts to the atmosphere, a detailed analysis of which is presented in Section 5.

4.4. Summary of Parameter Influences. Based on the simulation results, the degree of influence of each parameter is shown in Figure 12 and is summarised below.

(i) The supply pressure has the greatest influence on the boost ratio; the boost ratio increases with supply pressure.

(ii) The regulator is useful for adjusting the boost ratio, which can be changed continuously.
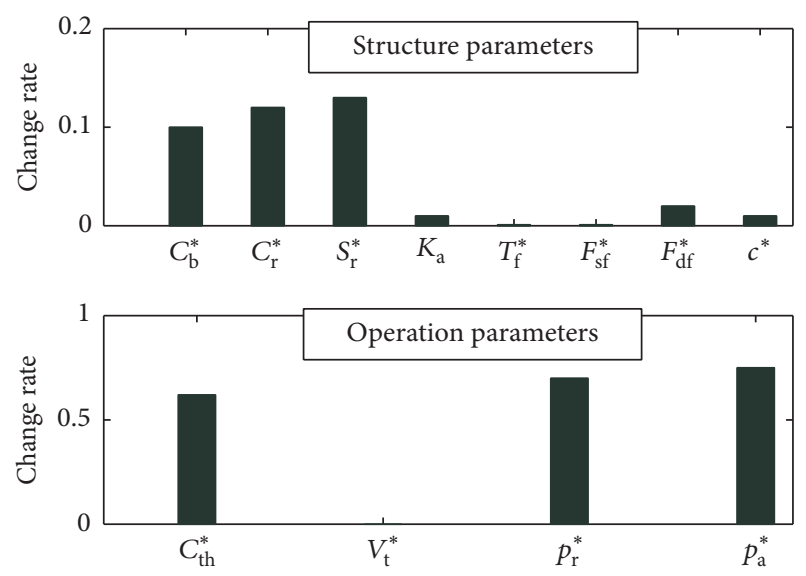

FIGURE 12: Change rate of each parameter.

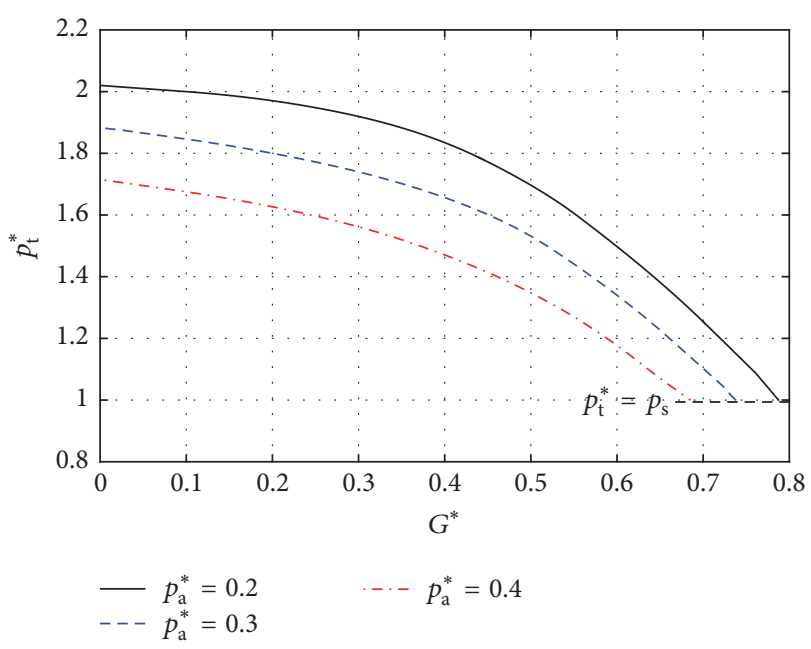

FIGURE 13: BVER flow-rate characteristics.

(iii) The boost ratio clearly decreases as the downstream load increases. When the (dimensionless) sonic conductance reaches 0.7 , the boost effect becomes negligible.

(iv) The boost ratio continuously increases with the recovery/boost chamber diameter ratio; however, the increase is imperceptible when recovery/boost chamber diameter ratio is $>1.6$.

(v) The larger the sonic conductance of the boost/ recovery chambers, the larger the boost ratio.

(vi) The cycle period, Kagawa coefficient, and viscous friction coefficient have little effect on the boost ratio.

In Figure 12, the change rate is the ratio of the output pressure change as each dimensionless parameter is changed from its reference value to its maximum one, with the output pressure remaining approximately constant. This is useful for evaluating the design influence of each parameter.

The pressure-flow characteristics of the BVER system are summarised in Figures 13 and 14. Figure 13 shows that 


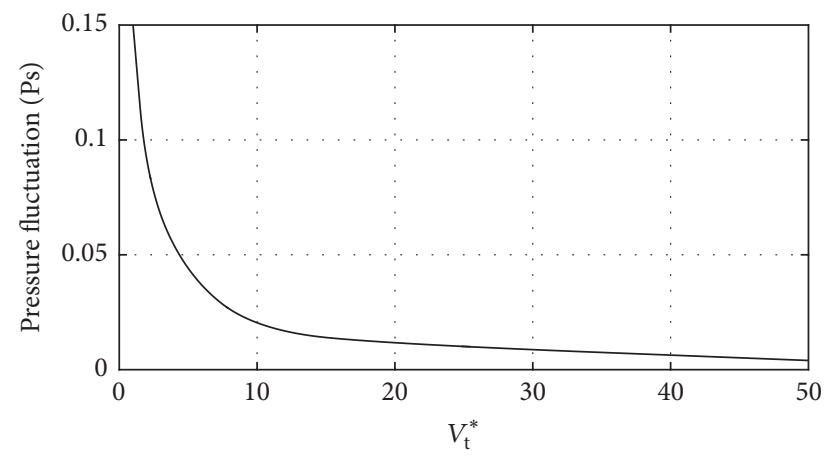

FIgURE 14: Pressure fluctuation in tank.

the BVER boost pressure ratio decreases as air consumption increases. The boost pressure ratio equals 1 when the (dimensionless) flow-rate consumption reaches 0.7 ; that is, the booster valve is useless.

Figure 14 shows the pressure fluctuation in the tank. Its magnitude is directly determined by the tank volume; when the (dimensionless) tank volume is 20 , the pressure fluctuation is $<1 \%$.

\section{Energy Efficiency Analysis and Experimental Study}

5.1. Energy Efficiency of Booster Valve. Exhausted compressed air is recovered and reused by the BVER, which helps enhance the boost ratio and also improves the energy efficiency. The boost ratio was discussed in the previous section. We are concerned here with BVER energy efficiency, which is defined as the ratio of the energy output to input. Thus, the definition of air power given in $[19,20]$ is introduced, from which the energy input of each stroke is

$$
E_{\text {in }}=\int_{0}^{t} p_{\mathrm{a}} Q_{\mathrm{a}} \ln \frac{p_{\mathrm{s}}}{p_{\mathrm{a}}} d t=p_{\mathrm{a}}\left(V_{\mathrm{bb}}+V_{\mathrm{da}}\right) \ln \frac{p_{\mathrm{s}}}{p_{\mathrm{a}}} .
$$

The dimensionless input energy is

$$
E_{\mathrm{in}}^{*}=p_{\mathrm{a}}^{*}\left(1+V_{\mathrm{b}}^{*}\right) \ln \frac{1}{p_{\mathrm{a}}^{*}} .
$$

Similarly, the energy output of each stroke becomes

$$
E_{\text {out }}=\int_{0}^{t} p_{\mathrm{a}} Q_{\mathrm{a}} \ln \frac{p_{\mathrm{t}}}{p_{\mathrm{a}}} d t
$$

and the dimensionless output energy is

$$
E_{\text {out }}^{*}=p_{\mathrm{a}}^{*} \int_{0}^{t} \frac{G_{\mathrm{t}}^{*}}{\rho_{0}} \ln \frac{p_{\mathrm{t}}^{*}}{p_{\mathrm{a}}^{*}} d t
$$

Thus, the BVER energy efficiency can be expressed as

$$
\eta=\frac{E_{\text {out }}^{*}}{E_{\text {in }}^{*}}=\frac{G_{\mathrm{t}}^{*} / \rho_{0} \ln \left(p_{\mathrm{t}}^{*} / p_{\mathrm{a}}^{*}\right) t_{\mathrm{p}}}{\left(1+V_{\mathrm{b}}^{*}\right) \ln \left(1 / p_{\mathrm{a}}^{*}\right)} .
$$

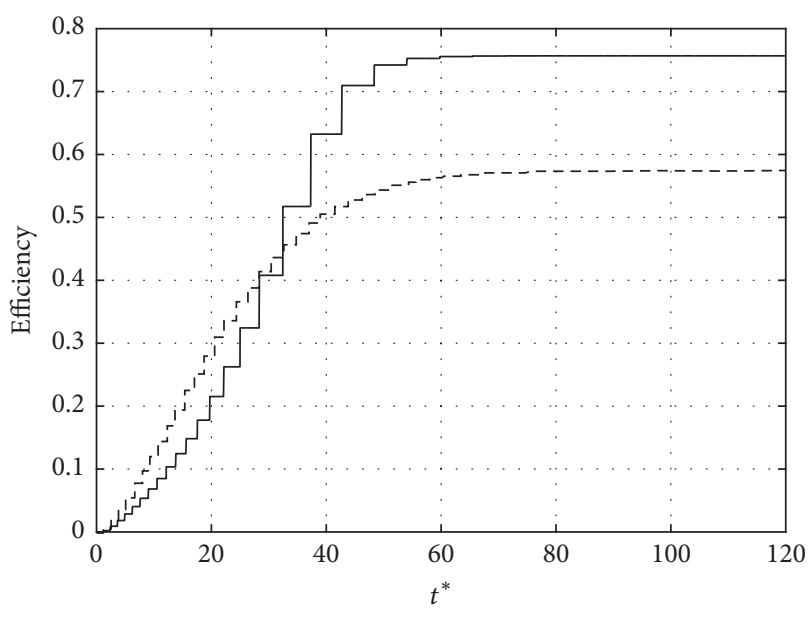

$$
\begin{aligned}
-C_{\mathrm{th}}^{*} & =0.1, p_{\mathrm{r}}^{*}=1.0, p_{\mathrm{a}}^{*}=0.4 \\
---C_{\mathrm{th}}^{*} & =0.3, p_{\mathrm{r}}^{*}=0.5, p_{\mathrm{a}}^{*}=0.2
\end{aligned}
$$

Figure 15: BVER energy efficiency.

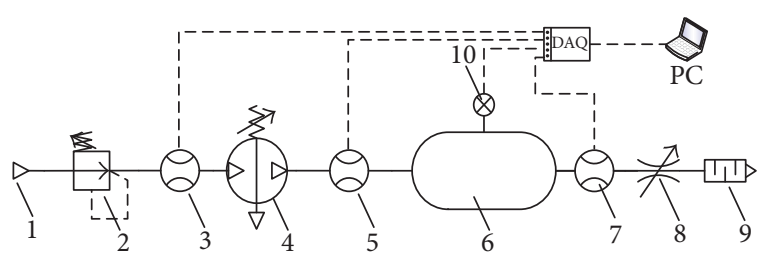

FIGURE 16: Schematic diagram of booster valve test: (1) air source, (2) regulator, (3) air power metre, (4) booster valve, (5) flow metre, (6) air tank, (7) air power metre, (8) throttle valve, (9) silencer, and (10) pressure sensor.

Based on these equations, the BVER efficiency of each stroke is as shown in Figure 15. It is clear that the BVER is initially inefficient; however, it improves as the booster valve stabilises. The difference in efficiency is $\leq 20 \%$ for two different operational configurations, so rational parameter allocation helps to enhance the efficiency.

5.2. Booster Valve Experiment. Air power is a function of pressure and flow rate and can be measured using an air power metre (APM) [21]. The main part of an APM is a responsive flow sensor that can translate pressure and flow rate into air power immediately.

The experimental circuit shown in Figure 16 consists of two APMs (APM-800S-L, TOKYO METER) that are accurate to $3 \%$. One is located at the upstream inlet of the booster valve, while the other is at the downstream of the tank rather than at the outlet of the booster valve. From the above analysis, we know that the flow rate out of the BVER is discontinuous, so it is difficult to measure the instantaneous air power accurately because of system response delay. However, the air power output from the tank is continuous and its fluctuation is small, so it is much easier to use it for precise measurement. 


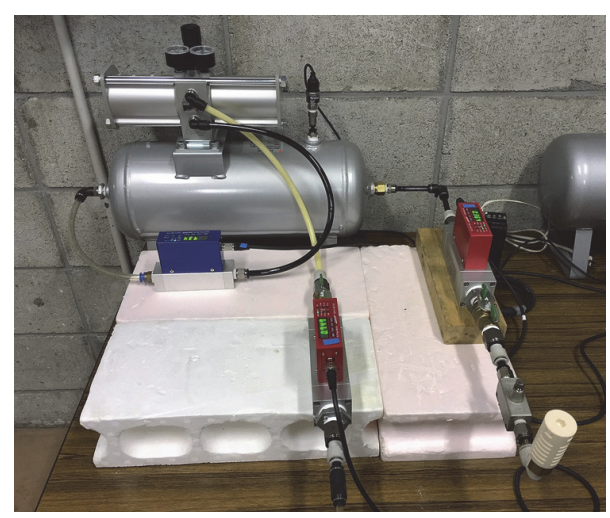

FIGURE 17: Energy efficiency test bench.

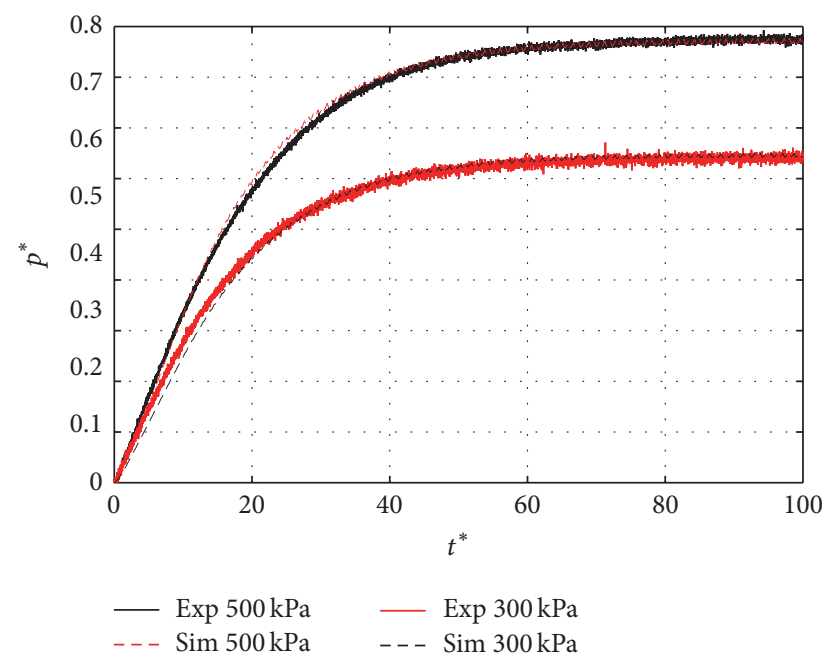

FIGURE 18: Dimensionless air power output.

A test bench was built as shown in Figure 17 based on the schematic diagram.

5.3. Test Results and Comparison. The dimensionless air power output from the tank is shown in Figure 18; the air power increases simultaneously with the supply pressure. The simulation has a short time delay due to the isothermal adjustment in the tank, which indicates that the simulation model works well and can reflect the characteristics adequately.

To verify the performance improvement of the BVER, a VBA booster valve (SMC Corp.) was used for comparison. The boost ratio and efficiency of the VBA and BVER are shown in Figures 19 and 20, respectively.

It is clear that the boost ratio increases by $15 \%-25 \%$ according to the supply pressure, and the efficiency increases by $5 \%-10 \%$. This proves that the compressed air recovered by BVER is being reused to enhance the boost ratio and efficiency, and the recovery chambers help restrain the pressure fluctuation.

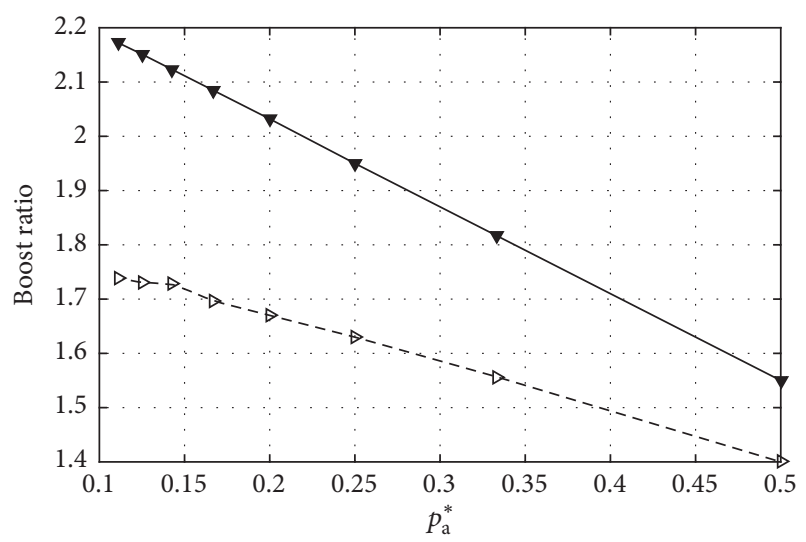

$\rightarrow$ BVER

$\rightarrow-$ VBA

FIGURE 19: Boost ratio comparison of VBA and BVER.

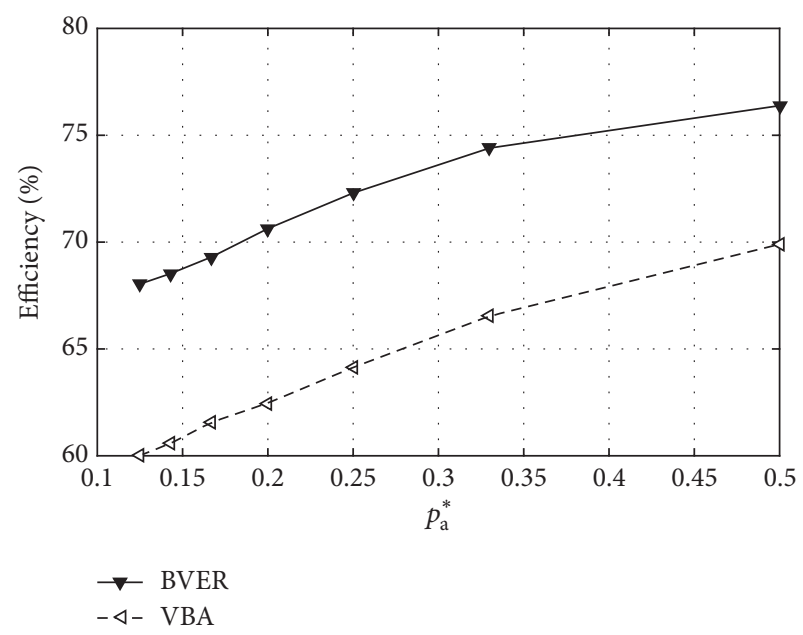

FIGURE 20: Efficiency comparison of VBA and BVER.

\section{Conclusions}

In this study, a new BVER was presented and its principles were discussed. A dimensionless mathematical model was proposed by properly selecting the reference values, whereupon the boost ratio and efficiency were calculated using Simulink. An experiment was conducted to contrast the BVER with a VBA valve, which validated the dimensionless model and proved that the BVER has better performance. The conclusions of this study are as follows.

(i) The tank pressure reflects the real boost ratio of the booster valve system, which should not be confused with the boost ratio of the booster valve.

(ii) The major structural parameters affecting the boost ratio are the sonic conductance and the diameter ratio.

(iii) The energy efficiency was influenced strongly by the operational parameters, with a maximum difference of $20 \%$. Hence, these should be selected carefully. 
(iv) The pressure boost ratio increases with the supply pressure, but the energy efficiency decreases.

(v) The BVER boost ratio increased by $15 \%-25 \%$ and its efficiency increased by $5 \%-10 \%$ compared to a booster valve without energy recovery.

This study determined the main parameters that affect the boost ratio of a BVER. Its characteristics, in particular, pressure response and efficiency, were analysed systematically. Energy recovery was shown to enhance the boost ratio and the efficiency. This study provides a suitable reference for booster valve design and energy saving and also helps optimise the structure of booster valves.

\section{Nomenclature}

$b$ : Critical pressure ratio

c: Viscous friction coefficient [Ns/m]

$c_{v}$ : Specific heat ratio at constant volume $[\mathrm{J} /(\mathrm{kg} \mathrm{K})]$

$C$ : Sonic conductance $\left[\mathrm{m}^{3} /(\mathrm{s} \mathrm{Pa})\right]$

E: Air energy [J]

$F_{\mathrm{f}}$ : Friction force $[\mathrm{N}]$

$F_{\text {sf }}$ : Maximum static friction force $[\mathrm{N}]$

$G$ : Mass flow rate $[\mathrm{kg} / \mathrm{s}]$

$h$ : Heat transfer coefficient $\left[\mathrm{W} /\left(\mathrm{m}^{2} \mathrm{~K}\right)\right]$

$\kappa: \quad$ Specific index $=1.4$

$L$ : Length of stroke [m]

$M$ : Piston mass [kg]

$p$ : Pressure $[\mathrm{Pa}]$

$P_{\mathrm{r}}$ : Pressure relief coefficient

$R:$ Gas constant [J/( $\mathrm{kg} \mathrm{K})]$

$S:$ Piston section area $\left[\mathrm{m}^{2}\right]$

$S_{\mathrm{h}}$ : Heat transfer area $\left[\mathrm{m}^{2}\right]$

$t$ : Time [s]

$u$ : Velocity of piston $[\mathrm{m} / \mathrm{s}]$

$V$ : Volume of chamber $\left[\mathrm{m}^{3}\right]$

$x$ : Displacement of piston $[\mathrm{m}]$

$\theta$ : Air temperature [K].

\section{Subscripts}

ba/bb: Boost chamber A/B

$\mathrm{da} / \mathrm{db}$ : Drive chamber A/B

$\mathrm{ra} / \mathrm{rb}$ : Recovery chamber A/B

$\mathrm{d}$ : Discharge chamber

c: Charge chamber

th: Throttle valve

0: $\quad$ Standard state $\left[20^{\circ} \mathrm{C}, 100 \mathrm{kPa}\right]$

1: Upstream of flow

2: Downstream of flow.

\section{Superscripts}

*: Dimensionless parameter.

\section{Main BVER Parameters}

(1) Structural Parameters

$C_{\mathrm{b}}^{*}$ : Sonic conductance when check valve fully opens

$C_{\mathrm{r}}^{*}$ : Sonic conductance of recovery chamber

$S_{\mathrm{ra}}^{*}$ : Area ratio of recovery to drive chamber

$K_{\mathrm{a}}$ : Heat transfer ability of BVER wall

$T_{\mathrm{f}}^{*}$ : Magnitude of piston mass product stroke

$F_{\mathrm{sf}}^{*}$ : Static friction of piston

$F_{\mathrm{df}}^{*}$ : Coulomb friction of piston

$c^{*}$ : Viscous friction force level.

\section{(2) Operational Parameters}

$C_{\mathrm{th}}^{*}:$ Load characteristic

$V_{\mathrm{t}}^{*}$ : Volume of tank

$p_{\mathrm{r}}^{*}$ : Regulator coefficient

$p_{\mathrm{a}}^{*}: p_{\mathrm{a}} / p_{\mathrm{s}}$, supply pressure.

\section{Competing Interests}

The authors declare that there is no conflict of interests regarding the publication of this article.

\section{Acknowledgments}

The authors acknowledge the SMC Corporation for its support with the test equipment and its guidance. The authors are grateful for the financial support of the China Scholarship Council and the Natural Science Foundation of China (51305313).

\section{References}

[1] P. Harris, G. E. O'Donnell, and T. Whelan, "Energy efficiency in pneumatic production systems: state of the art and future directions," in Leveraging Technology for a Sustainable World, pp. 363-368, Springer, Berlin, Germany, 2012.

[2] D. Šešlija, I. Ignjatović, and S. Dudic, "Increasing the energy efficiency in compressed air systems," in Energy Efficiency - The Innovative Ways for Smart Energy, the Future Towards Modern Utilities, M. Eissa, Ed., chapter 7, InTech, Rijeka, Croatia, 2012.

[3] R. Saidur, N. A. Rahim, and M. Hasanuzzaman, "A review on compressed-air energy use and energy savings," Renewable and Sustainable Energy Reviews, vol. 14, no. 4, pp. 1135-1153, 2010.

[4] H. Wang, W. Xiong, and X. Wang, "Research on the static characteristics of air driven gas booster," in Proceedings of the JFPS International Symposium on Fluid Power, vol. 2008, The Japan Fluid Power System Society, 2008.

[5] Z. Li, Y. Zhao, L. Li, and P. Shu, "Mathematical modeling of compression processes in air-driven boosters," Applied Thermal Engineering, vol. 27, no. 8-9, pp. 1516-1521, 2007.

[6] Y. Shi and M. Cai, "Working characteristics of two kinds of airdriven boosters," Energy Conversion and Management, vol. 52, no. 12, pp. 3399-3407, 2011. 
[7] Y. Shi, G. Jia, M. Cai, and W. Xu, "Study on the dynamics of local pressure boosting pneumatic system," Mathematical Problems in Engineering, vol. 2015, Article ID 849047, 11 pages, 2015.

[8] T. C. Li, H. W. Wu, and M. J. Kuo, "A study of gas economizing pneumatic cylinder," Journal of Physics: Conference Series, vol. 48, no. 1, pp. 1227-1232, 2006.

[9] Q. Xu, J. Sun, M. Cai, Y. Shi, and X. Fu, "A power recovery type pressure reducer in the high pressure pneumatic system," in Proceedings of the ASME/BATH Symposium on Fluid Power and Motion Control, American Society of Mechanical Engineers, Bath, UK, September 2014.

[10] K. A. Al-Dakkan, E. J. Barth, and M. Goldfarb, "Dynamic constraint-based energy-saving control of pneumatic servo systems," Journal of Dynamic Systems, Measurement and Control, vol. 128, no. 3, pp. 655-662, 2006.

[11] S. Merkelbach and H. Murrenhoff, "Exergy based analysis of pneumatic air saving measures," in Proceedings of the ASME/BATH Symposium on Fluid Power and Motion Control, American Society of Mechanical Engineers, Chicago, Ill, USA, October 2015.

[12] T. Takahasi and T. Kagawa, "Pneumatic booster valve: Japan," Patent 8-21404.1996-1-23.

[13] Q. Yu, M. Cai, Y. Shi, and C. Yuan, "Dimensionless study on efficiency and speed characteristics of a compressed air engine," Journal of Energy Resources Technology, vol. 137, no. 4, Article ID 044501, 9 pages, 2015.

[14] Y. Shi, J. Niu, M. Cai, and W. Xu, "Dimensionless study on dynamics of pressure controlled mechanical ventilation system," Journal of Mechanical Science and Technology, vol. 29, no. 2, pp. 431-439, 2015.

[15] Y. Shi and M. Cai, "Dimensionless study on output flow characteristics of expansion energy used pneumatic pressure booster," Journal of Dynamic Systems, Measurement and Control, vol. 135, no. 2, Article ID 021007, 8 pages, 2013.

[16] P. G. Harris, G. E. O’Donnell, and T. Whelan, "Modelling and identification of industrial pneumatic drive system," International Journal of Advanced Manufacturing Technology, vol. 58, no. 9-12, pp. 1075-1086, 2012.

[17] K. Toshiharu and C. A. I. Maolin, Measurement and Control of Compressible Fluid, Japan Industrial Publishing, Tokyo, Japan, 2010.

[18] T. Fujita, L. R. Tokashiki, Y. Ishii, and T. Kagawa, "Analysis of pneumatic cylinder responses driven by meter-out circuit," Transactions of the Japan Hydraulics \& Pneumatics Society, vol. 29, no. 4, pp. 87-94, 1998 (Japanese).

[19] M. Cai, K. Kawashima, and T. Kagawa, "Power assessment of flowing compressed air," Journal of Fluids Engineering, Transactions of the ASME, vol. 128, no. 2, pp. 402-405, 2006.

[20] M. Cai and T. Kagawa, "Energy consumption assessment and energy loss analysis in pneumatic system," Chinese Journal of Mechanical Engineering, vol. 43, no. 9, pp. 69-74, 2007 (Chinese).

[21] M. Cai and T. Kagawa, "Design and application of air power meter in compressed air systems," in Proceedings of the 2nd International Symposium on Environmentally Conscious Design and Inverse Manufacturing (EcoDesign '01), pp. 208-212, IEEE, Tokyo, Japan, 2001. 


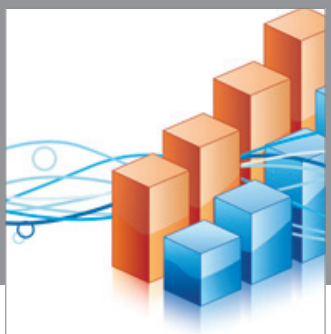

Advances in

Operations Research

vatem alat4

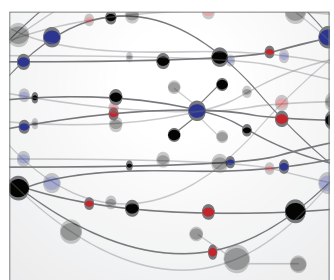

\section{The Scientific} World Journal
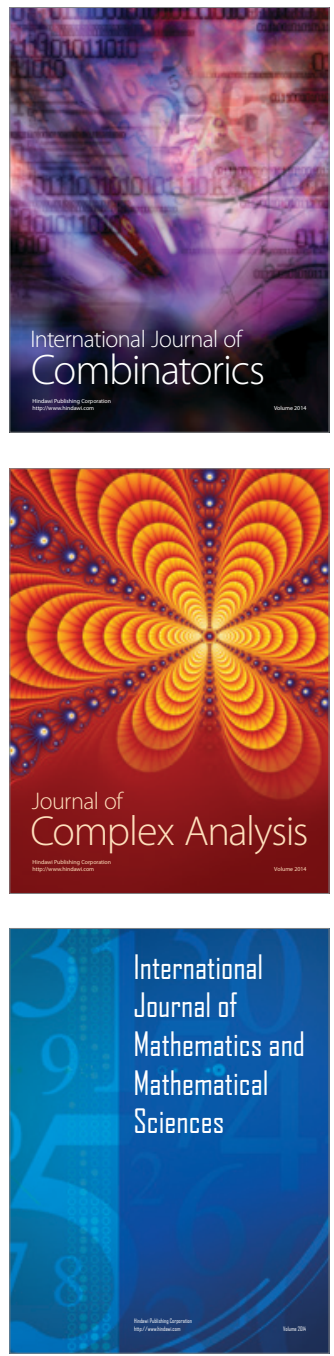
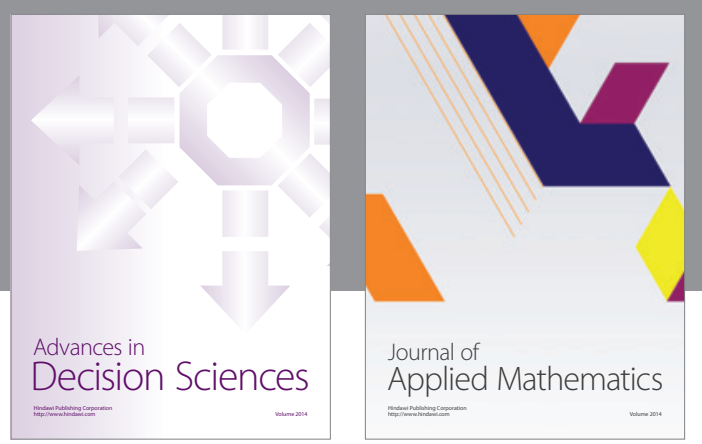

Algebra

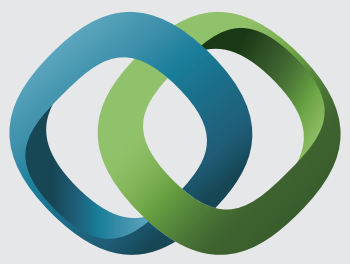

\section{Hindawi}

Submit your manuscripts at

http://www.hindawi.com
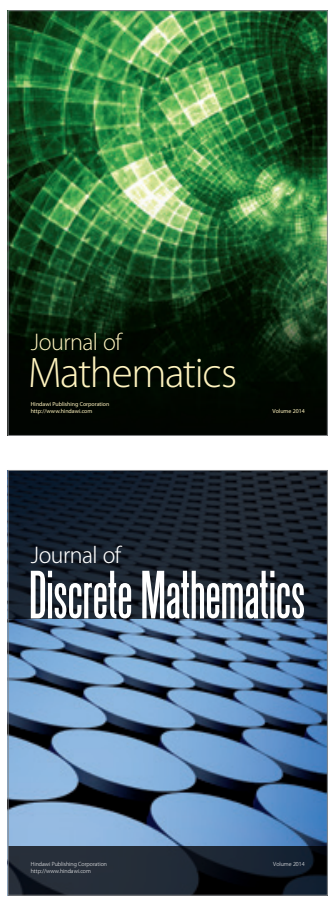

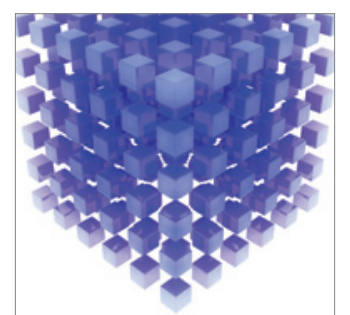

Mathematical Problems in Engineering
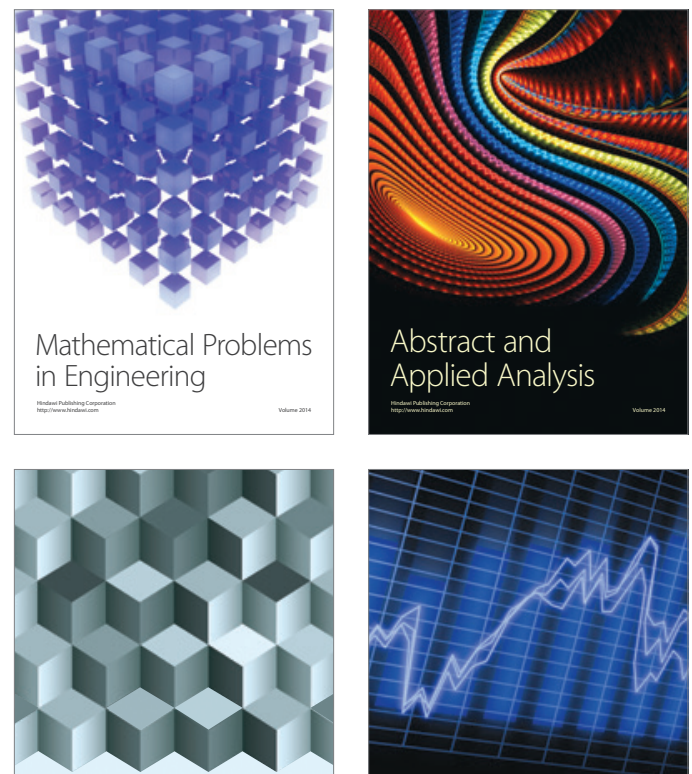

Journal of

Function Spaces

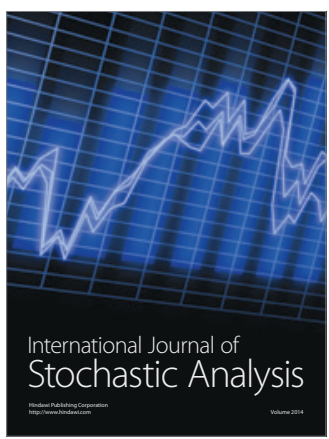

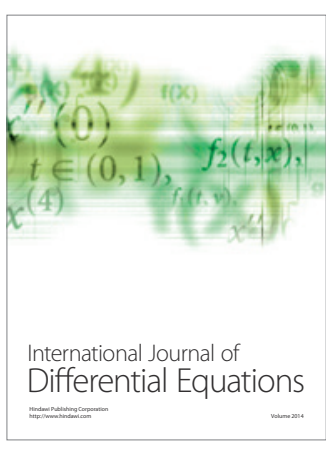
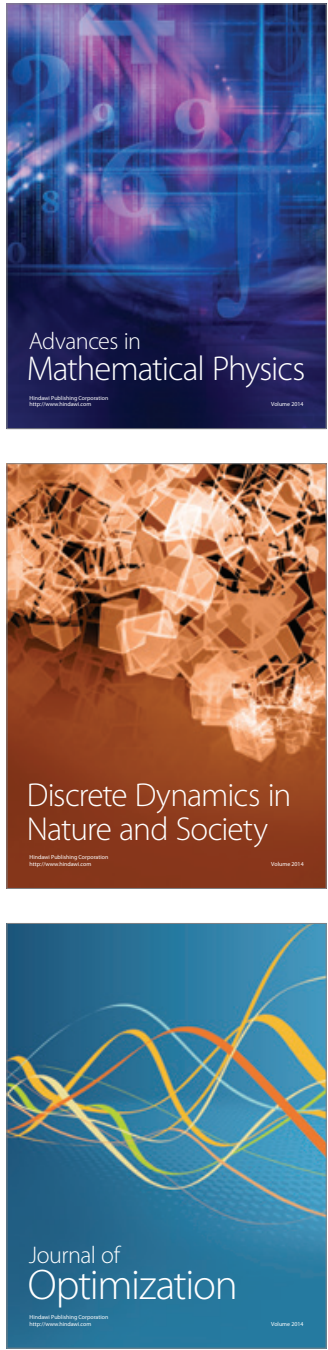